https://doi.org/10.17816/MAJ191S1236-239

\title{
THE IMPACT AND THE PREVENTION OF BURNOUT ON PSYCHIC ACTIVITY AND NERVOUS AND IMMUNE SYSTEMS
}

\author{
S. Radtchenko-Draillard
}

Faculty of Psychoanalytic Studies Sorbonne Paris City University- Paris Diderot University, Paris, France

radtchenkodraillards@gmail.com

The aim of my study is to analyze the causes and consequences of burnout on the dysfunction of psychic activity and weakening of the nervous and immune systems in their interaction. By presenting different research studies and my own analytical and practical results, this article traces the various orientations and identifies the symptoms, ranging from the quasi-normal state to the serious pathology in individuals suffering from burnout. The burnout methods and the psychotherapeutic techniques presented, which can generate the burnout cases, present a common backbone to the different approaches exposed in order to try to explain what this concept covers and the way it manifests itself.

Keywords: burnout; conflict; psychic activity; nervous and immune systems; prevention.

Introduction. Currently the problems of mental, emotional and physiological exhaustion, the issues of depersonalization and the reduction of personal accomplishment among individuals over-invested professionally are of great interest to researchers in human sciences and medicine. The burn-in is the first phase of the exhaustion syndrome with presenteeism which refers to an abusive presence in the workplace and the burnout (burning to the end) is the ultimate phase of global exhaustion syndrome in which the coping mechanisms are consumed under the influence of tensions and professional overinvestment. But the persistent under-occupation, marked by routine and boredom at work, can also lead narcissistic, ambitious and very well qualified individuals to a burnout or boreout (exhaustion by ennui). The aim of my study is to explain above that burnout is a result of complex multi-factorial, additional and interactive interactions between an individual, his or her professional environment and society in general that interact and influence each other continually. Freudenberger has observed in a recurring way the links between psychic activity and the weakening of the nervous and immune systems of the overinvested individuals in their work. Freudenberger (1974) thinks that the process of burnout consists of four phases: 1) idealistic enthusiasm, 2) stagnation, 3) frustration and depression, 4) apathy and despair. Freudenberger not only described the symptoms of burnout but also listed personality factors that predispose people to suffer from burnout. It is primarily "the dedicated and the committed" who are most likely to burnout [1]. Contrasting Freudenberger, which stresses the personal factors conducive to the appearance of a burnout, Maslach attributes them mainly to the professional environment and working conditions. According to the Maslach and Jackson three-dimensional model, of 'burnout syndrome includes: 1) professional exhaustion, 2) depersonalization, 3) diminution of personal achievement and the devaluation of the work it- self'. [2]. Based on the three dimensions of burnout, she developed the Maslach Burnout Inventory (MBI. [3] Other questionnaires exist, such as the Copenhagen Burnout Inventory (CBI) and the Oldenburg Burnout Inventory to measure worklife and health data collected from clinical signs observed by the occupational health service team.

The essential methods of preventing burnout bring include the treatment of various somatic disorders, restoring the interactions of nervous and immune systems with effective relaxation exercises. In case of burnout syndrome, medicine intervention (use of antidepressants, tranquilizers treatments for musculoskeletal disorders, nonsteroidal anti-inflammatory drugs, etc.) should be done in agreement with the doctor dealing. The controls of the working conditions by the doctors at work and psychologists must be systematic and effective. Human resources services, occupational health services in each society and organization have a preventive role to play in terms of screening for burnout, based on a set of both individual and collective signals (precisely, evaluating interpersonal conflicts, indicators related to the health and safety of workers, etc.). In the burnout prevention regimen, the psychotherapies (the Rogers helper relationship, Kernberg's empathy, Freudian psychoanalysis, Moreno psychodrama, Gestalt Therapy, etc.) are aimed at helping the person. As Freud points out in the psychoanalytic practice " For the work of analysis proceeds best if the patient's pathogenic experiences belong to the past, so that his ego can stand at a distance from them" [4].

Materials and methods. My analysis of the scientific burnout literature is based on a multiple approach. As I am interested in how burnout is investigated in the medical and psychologic field, I first identified all medical literature search for studies that investigate the burnout syndrome, using the PubMed database and others. This set of bibliographic databases references articles in the 
Table of essential dysfunctions, disorders and diseases observed during the burn-out

\begin{tabular}{|c|c|}
\hline Psychological and Psychoanalytic dysfunctions: & Psychosomatic disorders and diseases: \\
\hline $\begin{array}{l}\text { 1. Mental and cognitive exhaustion, memory } \\
\text { impairment, speech impairment, perceptive and } \\
\text { sensitive difficulties, decreased attention and } \\
\text { concentration, communication problems. }\end{array}$ & $\begin{array}{l}\text { 1. Physical exhaustion, chronic fatigue syndrome, } \\
\text { lack of energy, bodily pain, vestiges, muscle } \\
\text { tensions, headaches, sexual problems, ear ringing, } \\
\text { decreased hearing, sleep disturbances, sleep apnea, } \\
\text { vomiting, etc. }\end{array}$ \\
\hline $\begin{array}{l}\text { 2. Negative Attitude towards oneself, inferior } \\
\text { feeling, repetitive masochism, worthlessness, self- } \\
\text { repentance, loss of self-esteem, feelings of guilt, } \\
\text { permanent doubts, demotivation, etc. }\end{array}$ & $\begin{array}{l}\text { 2. Weakening of the immune system, increased } \\
\text { susceptibility to infections, colds and flu infections, } \\
\text { allergies, immune tolerance, inflammatory } \\
\text { reactions, general weakness of the immune system. }\end{array}$ \\
\hline $\begin{array}{l}\text { 3. Negative Attitude towards life, melancholy, post- } \\
\text { traumatic stress, disgust, daily frustration, anxiety, } \\
\text { suicidal thoughts, etc. }\end{array}$ & $\begin{array}{l}\text { 3. Heart palpitations, migraines, risk of developing } \\
\text { high blood pressure, cardiomyopathies, cardio- } \\
\text { renal disorders, tachycardia, myocardial infarction, } \\
\text { stroke, etc. }\end{array}$ \\
\hline $\begin{array}{l}\text { 4. Negative Attitude towards others (scorn, jealousy, } \\
\text { conflicts, harassment, cynicism, sadistic behaviors, } \\
\text { humiliations, sarcasm, etc. }\end{array}$ & $\begin{array}{l}\text { 4. Neurasthenia, neurocognitive disorders, different } \\
\text { neuroses, neuralgia, neurodermatitis, mental } \\
\text { disorders, depression, addictions (drugs, alcohol, } \\
\text { tobacco, medical self-treatment), etc. }\end{array}$ \\
\hline $\begin{array}{l}\text { 5. Loss of willingness to have contacts with } \\
\text { colleagues, family and friends, resignation, psychic } \\
\text { vacuum, depersonalization, etc. }\end{array}$ & $\begin{array}{l}\text { 5. Eating disorders, gastrointestinal disorders, gastric } \\
\text { ulcer, binge-eating disorder, anorexia, bulimia, } \\
\text { merycisme, sudden weight change, etc. }\end{array}$ \\
\hline
\end{tabular}

health sciences, particularly medicine, psychology, and neuroscience, and is a key resource for researches in these field. Specifically, I analyzed about 449 articles on burnout. According to this results and from the my point of view the burn-out is above all an 'interdependent consequence between the conflicts that exist in different levels "'[5]: 1) at the intrapersonal level (between antagonistic offensive and defensive drives, between the needs of his professional tasks and the means available to achieve them, etc.); 2) at the intersubjective level (between individuals who reveal differences in the satisfaction of each person's desires or the need to be recognized by his colleagues, etc.); 3) at the intra- groupal level (between hierarchy and subordinates which manifest disagreements in decision-making, etc.); 4) at the intergroup level (between social groups in the situation where they show aggression in competition, precariousness, etc.); 5) at the international level (between opposing goals and the means of their realization of the different countries, aggravated by economic crises, etc.). In order to summarize the impacts of burnout on health in general and the nervous and immune systems in particular found in the various researches, I have synthesized in the table the main dysfunctions, disorders and diseases occurred with the development of burn-out. (See Table).

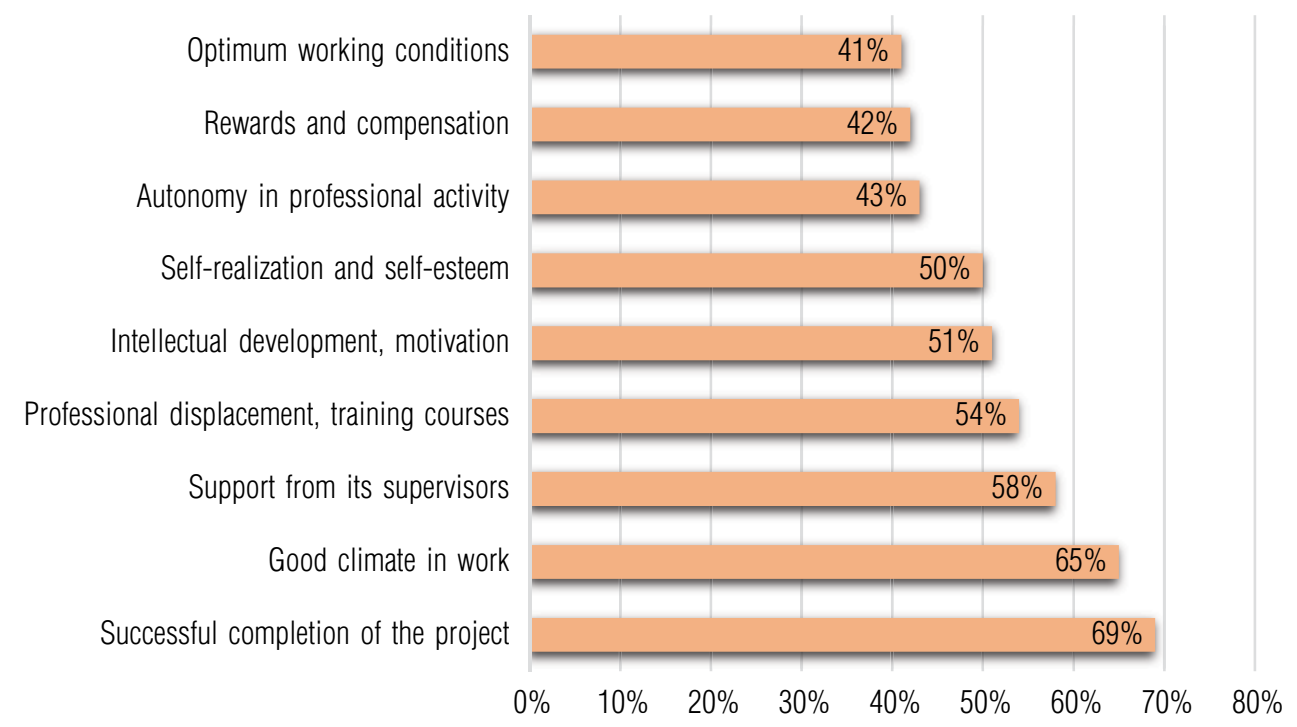

Figure. Essential Sources of Pleasure 
Concerned to regain a positive, optimistic and constructive attitude towards oneself and life. Emotional therapeutic stimulation and behavioral therapies also contribute to increasing the fixation of positive memories (satisfaction, happiness, pleasure) in individuals. Recall that the reaction to positive stress (eustress) or pleasure and evolution through its phases is often experienced as enjoyable and stimulating for the performance of individuals. In order to evaluate the effects of emotional therapeutic stimulation and analytical psychotherapy through the enhancement of pleasure I carried out a qualitative study (interviews) on the 119 managers (of the French companies and Foreigners located in Paris and its suburbs). According to my analysis, $75 \%$ of male managers and $69 \%$ women managers consider that pleasure is indispensable in the prevention of burnout. In addition, for $69.8 \%$ of managers the pleasure in the work increases the motivation and makes it easier to find problem solving, $81.3 \%$ of managers compare the pleasure with the satisfaction of being responsible for those of his team, $74.3 \%$ of managers the pleasure and the positive emotions necessary for the balance of the society. My study restores also the essential sources of pleasure in this professional work. (See Figure).

Conclusion. The analysis of burnout research has shown how a mental state has been socially and scientifically constructed and reproduced in the last years. Over time, the health sciences produced enough evidence to make burnout an important object of scientific enquiry and a challenge for public health. In my article I have shown that most studies focus on the causes and associated factors of burnout, in interactive link with the nervous and immune systems, and its prevention programs, but they do not adequately reflect without reflecting the psychological foundations of burnout or do not fully analyze the usefulness of this concept in a clinical context and in society at large. However, it is essential to also examine in this article all aspects of the onset of this syndrome, given the fact that many burnout studies find extremely high prevalence rates and that burnout is widely discussed in many modern and industrialized countries.

\section{References}

1. Freudenberger HJ. Staff burn-out. Journal of Social Issues. 1974;(30):159-165.

2. Maslach C. Burned-out. Human Behavior. 1976;(5):16-22.

3. Maslach C, Jackson SE. The measurement of experienced burnout. Journal of Organizational Behavior. 1981;(2):99-113.

4. Freud S. Analysis Terminable and Interminable. In: J Strachey. The Standard Edition of the Complete Psychological Works of Sigmund Freud. Vol. XXIII. Hogarth Press: London; 1964. P. 232.

5. Radtchenko-Draillard SV. L'étude psychanalytique de la résolution des conflits dans les interactions internationales et la négociation. Thèse de doctorat en psychologie. Université Sorbonne Paris Cité- Paris Diderot; 2016. P. 15-24.

6. American Psychiatric Association. Diagnostic and statistical manual of mental disorders. $5^{\text {th }}$ ed. Arlington: VA; 2013. 